\title{
Sustainable Project Management: Trends and Alignment
}

\author{
Mounir El Khatib, Khalil Alabdooli, Alsghairah AlKaabi, Salama Al Harmoodi \\ Hamdan Bin Mohammed Smart University, Dubai, United Arab Emirates \\ Email: drmunir.k@gmail.com
}

How to cite this paper: El Khatib, M., Alabdooli, K., AlKaabi, A., \& Al Harmoodi, S. (2020). Sustainable Project Management: Trends and Alignment. Theoretical Economics Letters, 10, 1276-1291. https://doi.org/10.4236/tel.2020.106078

Received: October 16, 2020

Accepted: December 12, 2020

Published: December 15, 2020

Copyright $\odot 2020$ by author(s) and Scientific Research Publishing Inc. This work is licensed under the Creative Commons Attribution International License (CC BY 4.0).

http://creativecommons.org/licenses/by/4.0/ (c) (i) Open Access

\begin{abstract}
Organizations in the contemporary competitive business environment encounter significant challenges in the course of managing various projects. Effective project management plays a significant role in fostering the competitive advantage of an organization, so the adoption of an effective and sustainable management strategy is fundamental in countering challenges. Although organizations today are accustomed to countering various project management challenges, adopting a sustainable project management strategy has proven to be one of the most significant challenges. Presently, organizations face the challenge of integrating sustainable practices and ensuring the safety of their stakeholders while simultaneously generating profits. Previous studies have failed to highlight the concept of sustainability in project management. Thus, this study investigates sustainability in project management, using three case studies to fill the existing research gap. The research reveals that the adoption of sustainable practices in project management helps to reduce costs, increase opportunities and profits, and facilitate organizational success. Nevertheless, organizations should understand that sustainability entails additional costs and commitment in terms of natural resources and finances to ensure project success.
\end{abstract}

\section{Keywords}

Sustainability, Project Management, Alignment, Trends

\section{Introduction}

Sustainable project management refers to planning, monitoring, and evaluating the project; controlling the project delivery and the associated support processes; and paying attention to the environmental, social, and economic aspects of the project life cycle. Sustainable project management aims to ensure that the 
project benefits the stakeholders; is performed in a transparent, fair, and ethical manner; and incorporates proactive stakeholder engagement (Institute Project Management Ireland, 2017). The achievement of project sustainability depends on the active role played by the project team and parties involved in the project, programs, and portfolios.

Nevertheless, while sustainability is one of the most significant issues in project management, it has been consistently overlooked in the past. Sustainable project management has only emerged recently, after project management professionals emphasized its importance in facilitating project success. Kivilä, Martinsuo, and Vuorinen (2017) highlight that sustainability is becoming increasingly significant in the delivery of projects because stakeholders are concerned about the ethical practices, environmental friendliness, and economic efficiency during the project life cycle. According to Martens and Carlvalho (2016), project management is a means of positively influencing the integration of sustainable practices into projects, which has aroused interest in the topic of sustainable project management. However, sustainability is challenging in large projects, which has prompted research into effective ways to integrate sustainability into project management. Kivilä, Martinsuo and Vuorinen (2017) note that the achievement of project goals depends on the efficiency of project control. Little research has focused on sustainable project management. Therefore, this research explores various case studies to investigate the adoption of sustainable project management and its strengths and weaknesses.

\section{Aims and Objectives of the Study}

This research aims to explain project management sustainability in contemporary organizations. Achieving this aim will require the fulfillment of the following research objectives:

1) To illustrate the concept of sustainability.

2) To demonstrate sustainability in project management.

3) To explain the principles of project management sustainability.

4) To show the relationship between strategy and sustainability.

5) To determine the importance of project management sustainability.

6) To identify the strengths and weaknesses of project management sustainability.

Achieving these six vital objectives will be fundamental in exploring the existing secondary data on the adoption of sustainable project management and analyzing its strengths and weaknesses.

\section{Literature Review}

Numerous studies have explored the existing trends and alignments in sustainable project management approaches. Because of the significant role of project management in any organization, researchers have shifted their focus to developing strategies and exploring trends that can be adopted to achieve sustainabil- 
ity in project management. According to Padalkar and Gopinath (2016), the analysis of current sustainable project management trends ensures project management's success. As such, this section of the study reviews the existing literature, guided by specific concepts that influence sustainability in project management.

\subsection{Current Trends and Alignments in Project Management}

The growth and development of technology has changed how projects are managed. Presently, project managers typically focus on the successful implementation of projects within the planned timeframe and without overstretching the initial budget (Navimipour \& Charband, 2016). The sustainable project management processes of planning, monitoring, implementing, and evaluating have equally undergone a paradigm shift to ensure accuracy and relevancy. As explained by Alvarez-Dionisi, Turner, and Mittra (2016), to foster successful project management processes and reduce various weaknesses, technologies such as artificial intelligence (AI) have been adopted. Over the years, the adoption of AI has been essential in fostering accuracy and facilitating the work of the project manager.

Additionally, current understandings of project management sustainability have been influenced by the incorporation of broader skillset to achieve efficiency. Zheng et al. (2016) postulate that to achieve sustainability in project management in the current business environment, a project manager must utilize a variety of skills. As such, members of a given project should have a diverse range of skills to achieve sustainability and ensure the successful implementation of the project. Moreover, Ul Musawir et al. (2017) hold that a hybrid project management approach that focuses on the diversity of the project members can foster competitive project management. By adopting a hybrid strategy, a project manager ensures that the needs of the project members are considered. Moreover, Zheng et al. (2016) explain that the adoption of a hybrid project management strategy fosters sustainability and ensures the success of the overall project management process. Because of the implications of these research trends and alignments, project managers should consider adopting the concepts analyzed by these researchers to achieve sustainability and reduce the challenges of poor project management.

\subsection{The Concept of Sustainability}

Sustainability entails three critical elements that must be adopted to achieve effective project management. These elements include the integration of economic, environmental, and social aspects; the integration of short-term and long-term perspectives; and the consumption of income instead of capital (van den Brink, Silvius, \& Köhler, 2012). The integration of the economic, environmental, and social goals is referred to as the triple bottom line perspective or the three pillars of sustainability (Martens \& Carvalho, 2016). Gachie (2019) claims 
that the economic pillar is generally regarded as more important than the other two pillars. The three pillars are interrelated. Therefore, gaining in one dimension is beneficial to the other two dimensions. For instance, social wellbeing and the wise use of environmental resources has positive economic effects. The economic pillar is particularly significant since it protects and sustains the project investors' capital, which promotes the need to maximize profit; reduce costs; increase revenue, profitability, and quality; and seek a return on investment.

The social perspective is the second pillar of project sustainability. It helps in the identification of the critical stakeholders whose needs and expectations catalyze project success. King IV (2016) asserts that both internal and external stakeholders-including the employees, trade unions, customers, and suppliers-are valuable organizational assets. However, many organizations fail to ensure the wellbeing of employees in particular, as they focus on exploiting them, inhibiting sustainable project management. In this regard, incorporating the social aspect is equally important as the economic aspect as it results in profit maximization. Lastly, the environmental or ecological pillar deals with the setting in which people work and the preservation and conservation of the environment. In the past, specific projects have been responsible for environmental degradation. As such, organizations must understand that social wellbeing and economic growth cannot be achieved without environmental conservation, as the three pillars significantly affect each other.

Sustainability also entails the integration of long-term and short-term goals. The critical notion of this aspect is that the economic dimension values short-term effects more than the long-term ones. In contrast, the social impacts and environmental degradation may not occur in the short-term but in the long-term (van den Brink, Silvius and Köhler, 2012). Lastly, sustainability is about consuming income instead of capital. Sustainability emphasizes that the business capital should remain intact, mainly for environmental and social reasons. Therefore, the company should not extract renewable resources at a higher rate than the rate at which they are renewed. Similarly, the business should not overexploit employees or offer payment that does not fit the amount of work done.

\subsection{Sustainability in Project Management}

The concept of sustainability in project management has evolved over the past decade. Therefore, it is important to highlight the essential aspects upon which project processes and procedures should be based. Lambuschagne and Brent, who revised the frameworks of project management, propose the inclusion of intra-generational and intergenerational equity as core principles of sustainable development (Agarwal and Karmal, 2015). As such, project managers should introduce both the spatial and temporal elements of sustainable development in project management practices. While these authors only highlight principles of sustainable project management in their literature, they present other sustaina- 
bility aspects that project managers should consider. They argue that project evaluation often focuses on financial indicators, with limited attention to environmental factors. They also fail to mention social factors. Therefore, Agarwal and Kalmar propose the development of a model that assesses projects based on the triple bottom line definition of sustainability. In addition, as part of social sustainability, they note that stakeholder participation is a critical assessment criterion.

On the other hand, Padalkar and Gopinath (2016) reveal that achieving sustainability in project management requires a critical assessment and evaluation of the current trends and alignments that foster successful implementation. According to Alvarez-Dionisi, Turner and Mittra (2016), to achieve sustainability in project management, effective evaluation and implementation of all of the three pillars of sustainability must be ensured. In this regard, Alvarez-Dionisi, Turner and Mittra (2016) insist that modern technological aspects must be incorporated to ensure that social, economic, and environmental impacts are effectively managed. As evidenced above, the three pillars are interdependent and require effective management to achieve sustainability. However, sustainability cannot be achieved without conducting a critical analysis and identifying suitable trends and alignments that a project manager must adopt. As explained by Zheng et al. (2016), project managers should consider adopting modern project management technologies to ensure that the three fundamental pillars of sustainable project management are achieved. Because of the roles played by these pillars in fostering the success of any project, analyzing and adopting relevant project management technologies and practices guided by the current trends and alignments leads to effective project management.

\subsection{Principles of Project Management Sustainability}

Achieving sustainable project management requires strict adherence to various principles. According to Silvius et al. (2017), the adopted project management principles that foster sustainability should be universal and focus on a specific area. Martens and Carvalho (2017) add that the validity of the project management principles should be based on their ability to empower the project team, their ability to conduct self-evaluation and validation, their history of achieving success, and their ability to inform a framework that identifies good project management practices. The following are some of the principles that foster sustainability in project management:

1) Commitment and accountability.

The emergence of the sustainable factors have more functional adherence technique overruled inside the ethical practices that are more contingent with what stakeholders of the organizations have to demonstrate about their pervasive acts in the functional technical emulsions. The absolute procurement of project management details tackles down the compliance of absolute ritual facts and what the managerial force of the industries have to manage within effective 
range of project management details.

2) Sustainability involves guaranteeing the rights of the critical stakeholders, enhancing ethical practices, ensuring equality, and compliance with the set legal framework (Green Project Management, 2019).

3) Ethics and decision-making. Sustainable project management supports organizational ethics and decision-making, with consideration for the universal principles. Moreover, it entails the implementation of mitigation and preventive measures against long-term societal and environmental impacts.

4) Integration and transparency. Project management should foster the interdependence of economic development, social integrity, and the protection of the environment (Green Project Management, 2019).

5) Enhancement of natural resources. This should be done by improving the development of technologies and resource-use practices.

6) Social and ecological equity.

7) Economic prosperity. This should be a focus of project management, which should adhere to the financial strategies, objectives, and targets set.

\subsection{Sustainability Strategies Adopted by Project Organizations}

Past research has highlighted the various strategies applied in improving and ensuring sustainability in project management. One strategy involves setting strategic and tactical sustainability goals. Aarseth et al. (2017) note that setting sustainability goals is critical in ensuring the alignment of projects with overall organizational strategies. The authors note that sustainable development facilitates the alignment process between project management and business strategy. They recommend organizations to pay attention to sustainability issues when developing project strategies and to focus on instances where sustainability issues align with other concerns.

A second strategy is for organizations to establish sustainable supplier practices to ensure the sustainability of their projects. The project owner should set the guidelines to facilitate the adoption of sustainable practices (Aarseth et al., 2017). These guidelines should focus on the minimization of resource consumption by maximizing re-use, promoting the use of renewable resources, protecting the natural environment, enhancing quality, and promoting socio-economic growth.

A third strategy is for organizations to emphasize sustainability in project design, which features strategic choices focused on designing sustainable projects. Project managers can adopt value management and life cycle management as key elements of project design to improve sustainable performance. The provision of sustainability indicators is an effective way to ensure sustainability from the project design phase to the completion of the project. Organizations must also formulate sustainability policies, influence sustainable project practices, and develop sustainability competencies by ensuring that project teams have adequate knowledge and skills pertaining to sustainability project management. 
Project teams can also benchmark from other sustainable projects executed in the past and adopt the required practices and procedures in implementing sustainable project management.

\subsection{Dimensions of Sustainability}

Certain dimensions of sustainability are critical in understanding the impact of sustainability on project management. Firstly, sustainability entails the integration and balance of social, environmental, and economic aspects. Thus, it must satisfy the three pillars of sustainability. Secondly, sustainability involves both local and global orientation. Silvius and Schipper (2014) note that international stakeholders-including competitors, suppliers, and customers-influence organizations. Moreover, the actions of the organization have economic, social, and environmental impacts, both locally and globally. Therefore, to address the interlinked processes, sustainable development should be integrated across the local and global levels. Silvius and Schipper (2014) also note that sustainability should involve stakeholder participation-organizations should ensure proactive stakeholder engagement through dialogue and consensus. Sustainability should also reduce risk by implementing mitigation measures to prevent damage. Risk reduction should not only focus on financial aspects but also on societal and environmental aspects. Finally, sustainability should focus on waste reduction, including elements such as overproduction, waiting time, transportation, inefficient processing, unnecessary inventory, excess movement, and defects. Eliminating waste is a significant step toward cost reduction and prevention of losses.

\subsection{The Importance of Sustainability in Projects}

Sustainable project management is essential to facilitate the successful execution and completion of projects, as well as to promote the success of the company. The first reason why sustainable project management is essential is risk management. Projects are often vulnerable to uncertainties, especially when they are situated in a social or environmental setting. Sustainability helps in risk mitigation, assessment, and management to prevent issues before they occur. The efforts to mitigate risks are placed under the sustainable development plan to ensure that the organization does not waste human and economic resources (Okeniyi, 2015). Secondly, sustainability enhances project quality, especially in terms of the material used in project execution. The enhancement of quality helps in reducing project depreciation, thus providing value to the stakeholders. Sustainability in project management is also significant in giving the project a competitive advantage over other projects. The adoption of sustainability practices allows projects to rank highly; therefore, they are more likely to be considered by investors and stakeholders. Thus, projects that employ sustainability practices are likely to become successful as they become highly competitive.

Sustainability is also vital for value provision. The adoption of sustainable practices allows stakeholders to see the value of the project, thus prompting 
them to support the project. Moreover, sustainability enhances project quality, increasing its value among the stakeholders and its likelihood for success (Okeniyi, 2015). Lastly, sustainability is essential for project preservation. Sustainable practices in project management ensure environmental conservation and the wellbeing of the communities in which the projects are executed. Therefore, the environment, as well as the people's health and wellbeing, remain preserved when organizations adopt sustainable project management practices.

Lastly, sustainability in projects ensures overall success. By achieving sustainability, a project manager ensures that the processes of planning, monitoring, implanting, and evaluation are effectively conducted (Carvalho \& Rabechini Jr., 2017). This concept ensures that the economic, social, and environmental aims of a given project are fully achieved. Thus, sustainability in projects minimizes the mismanagement of resources and ensures that the project management process is conducted according to the initial plans. Additionally, sustainability guarantees the overall success of a project because it ensures the adopted processes and other deliverable concepts align with the stakeholders' demands (El-Halwagi, 2017). As stated above, in a sustainable project, it is easy for the manager to minimize risks and align various processes aimed at achieving the primary objectives of the stakeholders. The success of any project is determined by timely completion within the initial budget. In this regard, adopting sustainability in project management is fundamental in achieving the project's overall success.

\section{Hypothesis}

Sustainability has major inclinations in the field of project management that fosters the spark to organizational value and the specific endearment for industrial entities depending on the lower risk factors. The significant change in the sustainability concerns is dependent on functional financial factors such as monetization and depreciation rates that create a roadmap for reduced risk circulations. Moreover, competitive advantage has procured the feasible interventions in project management that speculates the low dependency in the manufacturing field while also getting affected by resource depletion factors. The interdependency of project management on sustainability creates a pathway for more realistic yet manageable state of functional environmental state.

This research tests the following hypotheses:

$H 1$ - The implementation of project management sustainability increases organizational value and reduces risks.

A project's sustainability can increase organizational value and reduce risks. McKinsey indicates that the value at stake from sustainability concerns can be as high as $70 \%$ of earnings before interest, amortization, depreciation, and taxes. Risks are experienced in manufacturing due to resource depletion. One particular resource that is depleted is water, which is used inefficiently as it is considered a free material. In the UAE, this resource is used carelessly. 
H2-The application of project management sustainability gives companies a competitive advantage.

A sustainable business can generate income from sources other than the usual sales of goods and services, from revenue opportunities such as the sale of by-products, emission rights, sustainable technologies, and process management knowledge (von Rosing, Scheer, \& von Scheel, 2015). The implementation can be linked to sustainable brand and sustainable marketing and communications to make customers and stakeholders aware of its sustainable performance.

H3 - Sustainability can improve project outcomes.

A project can be improved via sustainability by regularly improving the quality of policies, data analysis, and objectives. Meeting new requirements, ease of future maintenance with the changing environment. Projects should be realistic, attainable, and feasible to be sustainable.

\section{Secondary Data}

The secondary data for this research is obtained from three case studies of organizations that have adopted sustainable project management. Martens and Carvalho (2016) present the case study of four companies-Organizations A, B, $\mathrm{C}$, and D. Organization A has a clear set of project processes with a clear definition of responsibilities. Organization B applies various project management practices, but the organization is still trying to improve and expand project management processes. Organization $\mathrm{C}$ has applied project management globally for several years, in both its United States enterprise and its business units across the world. Lastly, Organization D executes project management in two ways: firstly, projects are ISO9001 certified and audited based on item 7.3 of this standard; secondly, new projects are outside the scope of certification, so the company uses specific project management tools to certify them.

Regarding sustainability, Organization A has adopted sustainable practices to become more environmentally friendly and promote change within the company. Organization B is working toward the adoption of sustainable practices in the implementation of systematic work practices and in requirements for quality, health, safety, and the environment. Organization C's mission highlights sustainability and safety. The company's sustainable practices are mainly based on resource use and waste minimization through recycling. Lastly, Organization D has sustainability practices highlighted in its mission. Therefore, the company ensures that in executing its projects, it adheres to the needs of the stakeholders, legal requirements, and environmental protection.

The study by Martens and Carvalho (2016) investigated how organizations are introducing sustainability into project management and how these efforts impact project success. Through the case study of four organizations, the study revealed the use of standard project management methods and sustainability in the initiation, planning, development, and completion of projects. The study found that projects experienced a slight increase in project success, showing that or- 
ganizations were interested in improving and enhancing their technologies for better performance concerning sustainability. The results of the study gives effective research based findings that helps contributing the study for effortless leads in the development and project management sector that deals with effective management methods in order to create abundant resources for our study to gather data from. The functional maintenance of the sustainability revelations in the domain of project management has provided the researchers with various performance and project detailed speculations for tackling the findings of this study.

The second case study explores the University of Applied Sciences Utrecht's integration of sustainability in project management. The project is known as Duurzame Uithof, which focuses on the development of the entire Uithof area toward a sustainable Utrecht Science Park by 2040. The project is motivated by the need to create a sustainable Utrecht region. Duurzame Uithof's goal is to be a laboratory for innovative sustainable measures in terms of energy, water, mobility, and construction. Therefore, the focus is on reducing the amount of energy consumed by businesses, facilitating the transition away from fossil fuels, optimizing the water cycle, and minimizing waste. It promotes the use of bicycles and public transport to reduce environmental impacts from carbon emissions from personal cars. It encourages the sustainable construction of new buildings and renovation of existing ones (Goedknegt, 2014). The results of the case study demonstrate that sustainability in project management requires the successful involvement of critical stakeholders. The research also reveals that the project manager plays a significant role in ensuring the successful adoption of sustainable practices. Moreover, the adoption of sustainable practices is dependent on the knowledge and competencies of the project team.

The transforming study interventions have helped in generating effective result postulants that we have compiled for this study and to effectively reduce the impact of harmful and toxic chemical emissions in the environment with major and remote facilitative practices. The significant change in the environmental dealings under effective project management concerns have helped in adopting sustainable modes for industrial activities.

The third case study is the project titled "Open Remote of the Finalist IT group in Beijing". This case provides opportunities for the consideration of sustainability aspects. The findings were based on interviews with the manager of Finalist Beijing and the project manager of Open Remote. The researcher utilized Silvius and Schipper (2014)'s maturity model to analyze how sustainability is considered in the Green IS project known as Open Remote. The data sets were categorized by people, profits, and the planet. In terms of the people category, the company maximized sustainability in terms of fair work, wages, and the wellbeing of the employees (Silvius \& Nedeski, 2011).

The managerial association of the sustainability practices has leveraged the profit gains into the effective gains for basic achievement in the maturity analy- 
zation that works effectively for most of the user intelligence perseverance modes. The feasible interventions have overloaded the basic stats about project management techniques and its perseverance in the domain of sustainability and user friendly environment.

The company implemented labor practices, health and safety, and equal opportunity. Regarding the profit category, the company instigated sustainability practices in terms of products and services, leading to the achievement of $75 \%$ sustainability. Lastly, regarding the planet category, the company scored higher than in the profit category, having considered environmental conservation and sustainable business processes.

The resentful purpose of the case study has been rigorously preserved through categorical conversion of data statistics that elaborates the service achievement for effective maintenance on the labor practices as well as the sustainable business processes.

\section{Strengths and Weaknesses}

\subsection{Strengths}

The integration of sustainability into project management benefits organizations in various ways. According to Kahachi (2017), sustainability in project management increases organizational value, creates opportunities, reduces risks, increases profit, and reduces costs. The integration of sustainability allows companies to penetrate new markets, creating opportunities for increased revenue generation.

Moreover, sustainability in organization management facilitates product differentiation, which gives companies a competitive advantage. This increases a company's chances of attracting customers and increasing sales. Lagas (2015) states that sustainable practices make companies more marketable because modern consumers are conscious of the environment. In this regard, sustainable organizations strengthen their reputation, which attracts a higher number of customers and increases sales.

Sustainability reduces risks associated with projects and the business in general because risk management practices are part of the sustainability plan. Thus, project managers can detect risks early and develop mitigation measures to prevent losses for the company (Lagas, 2015). Sustainability also reduces costs in terms of resources such as energy and finances. Energy is a significant part of project management and project execution (Kahachi, 2017). However, sustainable practices emphasize the conservation of such resources, allowing the company to minimize the amount spent on them. Sustainability also advocates for the use of renewable energy, making energy costs cheaper. Sustainability enhances process efficiency, which enables companies to minimize costs associated with production and other processes within the project execution phase. 


\subsection{Weaknesses}

While sustainability in project management is highly beneficial for businesses, there are also various drawbacks. Firstly, sustainability incurs additional costs to increase knowledge and competencies concerning sustainability and to implement a sustainability plan within the organization (Thomas, 2019).

Secondly, the implementation of sustainability in project management requires high commitment in terms of resources such as time and money. This can be tiresome to the project teams as the outcomes of sustainability focus on the long-term rather than the short-term.

Lastly, the process is costly for smaller companies, especially for startups, due to the additional costs involved. To this end, such companies may be unable to adopt sustainability practices in project management effectively.

\section{Conclusions and Recommendations}

\subsection{Conclusion}

This research shows that projects make a significant contribution to the sustainable development and success of organizations. Therefore, it is imperative for organizations in the contemporary world to consider formulating relevant projects to counter the challenges of stiff market competition and achieve success in the UAE market. However, this study equally shows that the success of any project, which plays a fundamental role in fostering the competitiveness of an organization, is equally dependent on its ability to be sustainable. As a result, the concepts of sustainability adopted by any project manager should be reflected in projects throughout the management process. This study also shows that organizations that implement sustainability in project management are more likely to achieve success than those that adopt projects that do not consider sustainability. As evidenced by the existing literature, the importance of sustainability in project management is grounded in the three pillars of sustainability. Each project management process should consider the sustainability pillars of environmental, societal, and economic factors. Considering these three pillars is fundamental in minimizing various risks and setbacks that hinder successful project management. In this regard, project managers and other project team members must understand the interrelation between the three pillars and ensure that they are balanced. Overemphasis should not be placed only on the economic pillar because it might hinder the achievement of the other two pillars.

This research additionally concludes that organizations that wish to be successful in the current business world should adopt sustainable project management practices. Adopting these sustainable strategies plays a significant role in ensuring that an organization gains a competitive advantage. The findings of this research demonstrate that the implementation of sustainable project management increases the organizational value and reduces risks, thus ensuring that an organization achieves and maintains its competitive advantage and improves the general outcome of projects. Notably, the findings of this study prove the three 
hypotheses that were initially developed to guide the process of the research. Additionally, evidence from this research meets all of the six initial objectives of this research.

The implementation of sustainability in project management positively affects the whole project by easing future access to capital in managing projects. Additionally, the adoption of sustainability in project management improves customer loyalty, motivates employees, and boosts their morale and productivity. This concept is important because it improves supply chain outcomes, fosters organizational development, and improves the general operational performance and long-term organizational efficiencies. The study also shows that adopting sustainability in organizational project management adds value for stakeholders, reduces general business risks, and improves the recruitment and retention of talented employees. In this regard, organizations should consider adopting sustainability in the course of project management.

\subsection{Recommendations}

This study emphasizes the importance of adopting sustainable project management. The implementation of sustainable project management in the UAE requires the adoption of specific policies.

Firstly, the government must develop legislation and regulations to ensure sustainability in project activities. Regulations would ensure the easy adoption of sustainability, hence fostering effective project management. Secondly, there is a need to develop a staff sustainability action plan guided by the sustainability concepts discussed in this study. An action plan would foster the effective incorporation of sustainability into project management in various organizations across the UAE. Organizations in the UAE should also seek to improve the general quality of their systems, in particular the areas of policy, objectives, audit results, and data analysis. These should be redefined before sustainable project management can be adopted.

The fourth recommendation is to incorporate awareness into strategic decision-making processes to achieve sustainability. The fifth recommendation is for organizations in the UAE to implement labor practices, health and safety, and equal opportunities in order to achieve sustainability.

The use of standard project management methods and sustainability in the initiation, planning, development, and completion of projects should be considered by organizations in the UAE. Lastly, the research recommends the continuous review of global technological development to identify trends and alignments that foster project sustainability. For instance, sustainability in project management must be up-to-date and should adopt the front-end and back-end or direct engagement of stakeholders.

\subsection{Limitations}

There are many limitations associated with the detailed orientation of project 
management details while sustainability holds effective and beneficial position in this sector shadowing as various drawbacks. For instance, the involvement of additional costs and the less pervasive knowledge competencies have tendered organizational resources (Thomas, 2019).

Moreover, the implementation of sustainability in project management requires high commitment in terms of resources such as time and money. This can be tiresome for the project teams that play the outcomes of sustainability to have more focus on the long-term rather than the short-term. Whereas, the process is costly for smaller companies, especially for startups, due to the additional costs involved. To this end, such companies may be unable to adopt sustainability practices in project management effectively.

\section{Conflicts of Interest}

The authors declare no conflicts of interest regarding the publication of this paper.

\section{References}

Aarseth, W., Ahola, T., Aaltonen, K., Økland, A., \& Andersen, B. (2017). Project Sustainability Strategies: A Systematic Literature Review. International Journal of Project Management, 35, 1071-1083. https://doi.org/10.1016/j.ijproman.2016.11.006

Agarwal, S., \& Karmal, T. (2015). Sustainability in Project Management: Eight Principles in Practice. Dissertation, Umeå: Umeå University.

Alvarez-Dionisi, L. E., Turner, R., \& Mittra, M. (2016). Global Project Management Trends. International Journal of Information Technology Project Management, 7, 54-73. https://doi.org/10.4018/IJITPM.2016070104

Carvalho, M. M., \& Rabechini Jr., R. (2017). Can Project Sustainability Management Impact Project Success? An Empirical Study Applying a Contingent Approach. International Journal of Project Management, 35, 1120-1132. https://doi.org/10.1016/j.ijproman.2017.02.018

El-Halwagi, M. M. (2017). A Return on Investment Metric for Incorporating Sustainability in Process Integration and Improvement Projects. Clean Technologies and Environmental Policy, 19, 611-617. https://doi.org/10.1007/s10098-016-1280-2

Gachie, W. (2019). Project Sustainability Management: Risks, Problems and Perspective. Problems and Perspectives in Management, 17, 313-325. https://doi.org/10.21511/ppm.17(1).2019.27

Goedknegt, D. (2014). Sustainability in Project Management A Case Study at the University of Applied Sciences Utrecht. PM World Journal, 1, 1-18.

Green Project Management (2019). Principles for Sustainable Project Management. https://www.greenprojectmanagement.org/gpm-standards/principles-for-sustainable-p roject-management

Institute Project Management Ireland (2017). Sustainability in Project Management. http://www.projectmanagement.ie/blog/sustainability-in-project-management

Kahachi, H. A. H. (2017). Sustainability and Project Management-The Drivers and Benefits. Wasit Journal of Engineering Sciences, 5, 87-103.

https://doi.org/10.31185/ejuow.Vol5.Iss1.67 
King, I. V. (2016). Report on Governance for South Africa. Pretoria: Institute of Directors Southern Africa.

Kivilä, J., Martinsuo, M., \& Vuorinen, L. (2017). Sustainable Project Management through Project Control in Infrastructure Projects. International Journal of Project Management, 35, 1167-1183. https://doi.org/10.1016/j.ijproman.2017.02.009

Lagas, B. (2015). Five Benefits of Embracing Sustainability and Green Manufacturing. https://www.nist.gov/blogs/manufacturing-innovation-blog/five-benefits-embracing-su stainability-and-green-manufacturing

Martens, M. L., \& Carvalho, M. M. (2016). The Challenge of Introducing Sustainability into Project Management Function: Multiple-Case Studies. Journal of Cleaner Production, 117, 29-40. https://doi.org/10.1016/j.jclepro.2015.12.039

Martens, M. L., \& Carvalho, M. M. (2017). Key Factors of Sustainability in Project Management Context: A Survey Exploring the Project Managers' Perspective. International Journal of Project Management, 35, 1084-1102. https://doi.org/10.1016/j.ijproman.2016.04.004

Navimipour, N. J., \& Charband, Y. (2016). Knowledge Sharing Mechanisms and Techniques in Project Teams: Literature Review, Classification, and Current Trends. Computers in Human Behavior, 62, 730-742. https://doi.org/10.1016/j.chb.2016.05.003

Okeniyi, J. O. (2015) Project Sustainability: Overview of Sustainability in Project Management.

https://www.researchgate.net/publication/309155554_Project_Sustainability_Overview _of_Sustainability_in_Project_Management

Padalkar, M., \& Gopinath, S. (2016). Six Decades of Project Management Research: Thematic Trends and Future Opportunities. International Journal of Project Management, 34, 1305-1321. https://doi.org/10.1016/j.ijproman.2016.06.006

Silvius, A. J. G., \& Nedeski, S. (2011). Sustainability in IS Projects: A Case Study. Communications of the IIMA, 11, 1-12.

Silvius, A. J. G., \& Schipper, R. P. J. (2014). Sustainability in Project Management: A Literature Review and Impact Analysis. Social Business, 4, 63-96. https://doi.org/10.1362/204440814X13948909253866

Silvius, A. J. G., Kampinga, M., Tufinio, P. S., \& Mooi, H. (2017). Considering Sustainability in Project Management Decision Making: An Investigation Using Q-Methodology. International Journal of Project Management, 35, 1133-1150. https://doi.org/10.1016/j.ijproman.2017.01.011

Thomas, G. (2019). Advantages and Disadvantages of Sustainable Development. https://www.lorecentral.org/2018/07/advantages-and-disadvantages-of-sustainable-dev elopment.html

Ul Musawir, A., Serra, C. E. M., Zwikael, O., \& Ali, I. (2017). Project Governance, Benefit Management, and Project Success: Toward a Framework for Supporting Organizational Strategy Implementation. International Journal of Project Management, 35, 1658-1672. https://doi.org/10.1016/j.ijproman.2017.07.007

van den Brink, J., Silvius, G. G., \& Köhler, A. (2012). The Impact of Sustainability on Project Management. In H. Linger, \& J. Owen (Eds.), The Project as a Social System. Asia-Pacific Perspectives on Project Management (pp. 183-200). Victoria: Monash University Publishing.

von Rosing, M., Scheer, A.-H., \& von Scheel, H. (2015). The Complete Business Process Handbook: Body of Knowledge from Process Modeling to BPM (Vol. 1). Waltham, MA: Elsevier. 
Zheng, X., Le, Y., Chan, A. P. C., Hu, Y., \& Li, Y.K. (2016). Review of the Application of Social Network Analysis (SNA) in Construction Project Management Research. International Journal of Project Management, 34, 1214-1225.

https://doi.org/10.1016/j.ijproman.2016.06.005 